\title{
CHAPTER 16. SUBCRITICAL WATER EXTRACTION OF BIOACTIVE COMPONENTS FROM ALGAE
}

\section{Castro-Puyana, M. Herrero, J. A. Mendiola, E. Ibáñez*}

Bioactivity and Food Analysis Department, Institute of Food Science Research (CIALCSIC). Nicolás Cabrera 9, Campus UAM Cantoblanco, 28049 Madrid - SPAIN Corresponding author: elena@ifi.csic.es

Chapter abstract: Subcritical water extraction (SWE) is presented in this chapter as a potent and novel alternative to conventional solvent extraction processes for isolating bioactive components from algae. SWE is defined as the extraction with water at temperatures ranging from the boiling point to the critical point and at pressures high enough to keep the water in the liquid state throughout the extraction process. Water has many advantages when used as solvent since it is environmentally green and sustainable and can modify some of its physical and chemical properties by heating. Interesting real applications of this technology are discussed together with other applications with potential to be developed successfully under SWE conditions.

Key words: subcritical water extraction, pressurized water extraction, algae, SWE, PHWE 
Functional Ingredients from Algae for Foods and Nutraceuticals (Cap.16): 534-560 (2013) doi: 10.1533/9780857098689.3.534 isbn: 978-0-85709-512-1 
Functional Ingredients from Algae for Foods and Nutraceuticals (Cap.16): 534-560 (2013)

doi: 10.1533/9780857098689.3.534 isbn: 978-0-85709-512-1

\section{Contents:}

17.1 Introduction.

17.2 Principles of subcritical water extraction.

17.2.1 Extraction temperature

17.2.2 Extraction pressure

17.2.3 Extraction time

17.2.4 Other variables

17.3 Equipment requirements.

17.4 Applications to the extraction of bioactive components from algae; comparison to conventional processes.

\subsubsection{Antioxidants}

17.4.2 Antimicrobials and antivirals

17.4.3 Other bioactive products from algae in the frontier to be extracted

17.4.3.1 Carbohydrates or Saccharides

17.4.3.2 Bioactive peptides

17.4.3.3 Neuroprotective compounds

17.4.3.4 Pigments

17.4.3.5 Therapeutic and pharmacologic products

17.5 Conclusions and Future trends.

17.6 References. 
Functional Ingredients from Algae for Foods and Nutraceuticals (Cap.16): 534-560 (2013)

doi: 10.1533/9780857098689.3.534 isbn: 978-0-85709-512-1

\subsection{Introduction.}

As it has previously mentioned in previous chapters of this book, algae are

photosynthetic organisms that can be found in nearly any aquatic and terrestrial habitat.

They possess reproductive simple structures and can exist from unicellular microscopic organisms (microalgae) to multicellular organisms of large size (macroalgae).

Considering their huge biodiversity and the fact that many species remain unknown, it is easy to understand the interest on the discovery of novel biological active products from algae. Although a lot of research has been carried out on the development of processes for biofuel production using micro- and macroalgae biomass, including those using wastewater as nutrient source (Sturm et al., 2012; Day et al., 2012), another active field of research deals with the use of algae to extract high added value products for the food and pharmaceutical industry (Spolaore et al., 2006). In fact, it has been suggested that secondary metabolites produced by these organisms, when submitted to extreme conditions (changes of salinity, temperature, nutrients, UV-vis irradiation), provide with unique structures with important activities for human health such as antioxidant, antiviral, antimicrobial, hypocholesterolemic, anticarcinogenic, antiallergic, etc. (Li and Kim, 2011; Vo et al., 2012; Javed et al., 2011). Besides, algae can be considered truly natural bioreactors able to grow easily under certain conditions that can be also tuned to produce bioactives at large scale; many applications have been developed dealing with the exploration of marine microorganisms for biotechnological applications, including the production of bioactive compounds for pharmaceutical use, as well as the development of other valuable compounds such as enzymes, nutraceuticals and cosmetics. On the other hand, exploration and use of genomic and metagenomic resources is considered very useful for identification and production of new chemical 
Functional Ingredients from Algae for Foods and Nutraceuticals (Cap.16): 534-560 (2013) doi: 10.1533/9780857098689.3.534 isbn: 978-0-85709-512-1

structures of commercial interest (Imhoff et al., 2011). Undoubtedly, the combination of these possibilities, together with algae great biodiversity, makes the use of algae an almost unlimited field of research when seeking new bioactive compounds.

Another important aspect to be considered when dealing with obtaining bioactives from algae is the development of appropriate, fast, cost-effective and environmental-friendly extraction processes able to isolate the compounds of interest from these natural sources. In this chapter, we focused on the extraction of bioactives using subcritical water extraction (SWE or PHWE, pressurized hot water extraction). PHWE is a green processing technology using water at high temperature (above its boiling point) and pressure enough to keep water at liquid state at the operating temperature. Water can be considered the greenest solvent to work with, it has negligible environmental effect, non-toxicity to health and the environment and it is safe to work with and to transport. Therefore, water is the solvent to select in those applications in which polar protic solvents are needed, although considering the change in water properties with the temperature (for instance, the decrease in dielectric constant with increasing temperature), it is also able to extract medium polarity compounds (Turner and Ibáñez, 2011).

In this book chapter, basic aspects to be considered during SWE (or PHWE) will be discussed, such as the effect of the different factors (temperature, pressure and time) on the process, together with some equipment requirements. Moreover, some real applications of SWE to the extraction of bioactive components, such as antioxidants, from algae will be discussed and compared to traditional processes, while other applications with potential to be developed under SWE conditions will be presented and 
Functional Ingredients from Algae for Foods and Nutraceuticals (Cap.16): 534-560 (2013)

doi: 10.1533/9780857098689.3.534 isbn: 978-0-85709-512-1

critically discussed, with the idea of widening the vision on the possibilities offered by the PHWE technology in obtaining bioactive compounds from algae.

\subsection{Principles of subcritical water extraction.}

As mentioned, subcritical water extraction (SWE) refers to the advanced extraction technique based on the use of water at high temperatures (higher than the boiling point, $100^{\circ} \mathrm{C}$, and lower than the critical temperature, $374^{\circ} \mathrm{C}$ ) and pressures enough to maintain the waters' liquid state during the whole extraction process. This technique can be considered as a branch of pressurized liquid extraction (PLE), which is based on the same principles but using other solvents to carry out the extractions. As a consequence of the application of these conditions (high pressures and temperatures), faster extraction processes are usually obtained in which the extraction yield is normally higher than the one attainable at room conditions. The use of SWE has been suggested for the extraction of bioactive components from natural sources (Mendiola et al., 2007; Wiboonsirikul and Adachi, 2008; Herrero et al., 2006a). In this section, the influence of the main parameters involved in SWE is briefly described.

\subsubsection{Extraction Temperature}

Temperature is, undoubtedly, the most influencing parameter in SWE. The increase of water temperature will produce a series of effects, including an improved mass transfer as a result of the increment of the solubility of the compounds present on the matrix being extracted, as well as a decrease on the surface tension of water that allows a better penetration into the sample matrix. The change in viscosity is particularly relevant during the first $100{ }^{\circ} \mathrm{C}$ increase of temperature from ambient conditions. Moreover, the 
Functional Ingredients from Algae for Foods and Nutraceuticals (Cap.16): 534-560 (2013) doi: 10.1533/9780857098689.3.534 isbn: 978-0-85709-512-1

mass transfer kinetics will be also favored by the disruption of intermolecular forces (i.e., van der Waals forces, hydrogen bonds and dipole attractions) in the sample matrix. Nevertheless, the most important effect of the increment of liquid water temperature is the weakening of hydrogen bonds, resulting in a lower dielectric constant ( $\varepsilon$ ) (Ong et al., 2006). In fact, this value, taken as a measure of polarity, can vary from 80 (at room temperature) to values around 25 when is submitted to temperatures of ca. $250{ }^{\circ} \mathrm{C}$. This value is similar to the one presented by some organic solvents at room temperature, such as ethanol or methanol (Figure 1), and thus, the use of SWE could be an alternative to the use of this type of solvents in some applications.

However, in spite of the above-mentioned advantages, in a real SWE process aimed to the extraction of bioactives from a natural sample, water temperature does not have to be necessarily as high as possible. Instead, this parameter should be optimized and controlled carefully. The main reason is that when using high temperatures, other less desirable effects might also take place. Although, generally, an increase in the temperature produces the subsequent increase in the extraction yield, when dealing with bioactive compounds, too high temperatures could lead to the degradation of these compounds. Thus, the use of experimental designs to optimize the extraction temperature is always recommended. During this process, the qualitative and quantitative presence of bioactive is monitored. For instance, it has been observed how the extraction of phenolic compounds from Terminalia chebula plant can be favored with the increasing temperature until $180^{\circ} \mathrm{C}$. Higher temperatures lead to a loss of the phenolic antioxidants (Rangsriwong et al., 2009). Same observations have been reported for other natural antioxidants. 
Functional Ingredients from Algae for Foods and Nutraceuticals (Cap.16): 534-560 (2013) doi: 10.1533/9780857098689.3.534 isbn: 978-0-85709-512-1

Besides degradations, other reactions might also occur when increasing the extraction temperature. For instance, it has been demonstrated how during SWE processes Maillard, caramelization and/or thermooxidation reactions may occur (Plaza et al., 2010a; Plaza et al., 2010b) considering both, glycation model systems and real natural samples. In fact, it has been shown that the occurrence of those reactions leads to the formation of neoantioxidant compounds not naturally present in the sample being extracted. This point could be an additional advantage, since interesting compounds could be also formed during SWE processes. Nevertheless, caution is recommended in any case, as more studies are needed to assess the safety of the obtained extracts.

\subsubsection{Extraction pressure}

Pressure has an important effect and function in SWE processes, as it will be the parameter that will permit to maintain the water in the liquid state at high temperatures. For this reason, pressures of 50-100 bar are usually employed. These values are enough to keep the liquid state at the usually employed temperatures. However, although theoretically the pressure might exert a rupture effect on the sample being extracted, several works showed that pressure did not significantly influence the obtained results once it was enough to maintain the water in the liquid state (Herrero et al., 2005).

\subsubsection{Extraction time}

Extraction time in SWE is referred as the effective time in which the solvent is in contact with the sample being extracted at the desired temperature and pressure conditions. Some commercial instruments apply a heat-up time in order to allow the system to equilibrate at the target conditions. Extraction time starts once the extraction 
cell is filled with water at the selected temperature and pressure. In general, the extraction time needed to fully-extract a particular sample will depend on several parameters; one of the most critical is the type of extraction. The most frequent method employed is static extraction in which a certain volume of water, under the desired conditions of pressure and temperature, is maintained in contact with the sample for a given time. Thus, in static conditions, an equilibrium between the sample components still bound to the matrix and the water phase in which the components are already solubilized might be reached. If this is the case, the efficiency of the extraction procedure will not be increased beyond this point. Instead, some compounds' degradations could more easily occur. For this reason the careful optimization of the static extraction time applied is of great importance. In general, relatively short static extraction times (5-20 $\mathrm{min})$ are applied for the extraction of bioactives from natural matrices. On the other hand, if the system is working on a dynamic mode, heated and pressurized water will be flowing into the extraction cell continuously. Theoretically, this mode will be more favorable for the complete extraction of the sample matrix as equilibrium is avoided. However, this dynamic mode is not free of shortcomings; in fact, generally higher volumes of water are employed and sometimes the obtained extract may be too diluted for analytical determination. Besides, if the aim is to achieve a dried extract, the elimination of higher volumes of water (either by freeze-drying or other heat-based methods) will mean more costly procedures.

\subsubsection{Other variables}

Besides the above-mentioned most-common variables, other different factors might have an important influence in SWE and, thus, need to be studied during the 
Functional Ingredients from Algae for Foods and Nutraceuticals (Cap.16): 534-560 (2013) doi: 10.1533/9780857098689.3.534 isbn: 978-0-85709-512-1

optimization of the process. An important variable to be considered if the extraction is performed under dynamic conditions is the flow rate. The flow rate will directly influence the extraction time needed to complete the process. An appropriate flow rate would permit a short contact between sample and solvent allowing the solubilization of the compounds of interest. At the same time it is advisable to have a flow rate not too high so that the extract is not too diluted. Some commercial instruments do not allow performing dynamic extractions. In those cases, the flow rate simply influences the time that will be necessary to have the extraction cell completely filled with pressurized heated water. Another alternative to emulate a dynamic extraction, when working with instruments only permitting static extractions, is the use of sequential extraction of the same sample. By using short extraction times in repeated extraction cycles, higher extraction yields could theoretically be achieved, avoiding the equilibrium between sample components and water. Another possibility is the use of different sequential cycles at diverse extraction conditions. This approach permits the extraction of different kind of components in each temperature step (from lower to higher temperature). It has been already observed that the sequential extraction of natural matrices from low (50 $\left.{ }^{\circ} \mathrm{C}\right)$ to high $\left(200^{\circ} \mathrm{C}\right)$ temperatures allow the attainment of extracts with different chemical composition (Rodríguez-Meizoso et al., 2006).

Other interesting parameter is the sample physical state. As in every extraction process, the efficiency will be higher as the contact surface is increased. Thus, the sample size should be also studied. Usually, for the extraction of solid dried natural matrices, a grinding procedure is previously performed. The particle size has to be appropriate to maximize the contact surface while avoiding the formation of preferential paths, that is, channels formed inside the extraction cell through which the solvent flows. In some 
Functional Ingredients from Algae for Foods and Nutraceuticals (Cap.16): 534-560 (2013)

doi: 10.1533/9780857098689.3.534 isbn: 978-0-85709-512-1

applications, the introduction of dispersants together with the sample in the extraction cell is employed to favor the uniform distribution of the solvent and to maximize the extraction yield. Of consideration is also the use of in-cell clean-up steps or in-line concentration procedures to improve selectivity. In these cases, the use of adsorbents might be of help in order to retain just some of the extracted compounds while favoring the extraction of the compounds of interest.

\subsection{Equipment requirements}

The basic instrumental requirements to perform SWE are not too complicated. In principle, a pump is needed to pump the water inside the extraction cell as well as to push the extract out, once the extraction is finished. This pump should be capable to achieve the desired pressure (normally, between 35 and 200 bar). The water employed for the extraction should be oxygen-free in order to avoid oxidation of the bioactives as well as to prevent cavitation in the pump. To do that, degassing by ultrasounds or helium purge are commonly employed. The next step will be the extraction cell that should have two on/off valves in order to be able to keep the extraction conditions stable and an oven to heat the extraction cell. The maximum working temperature in most instruments is around $200^{\circ} \mathrm{C}$. Lastly, a collecting vial is needed. Nevertheless, from this starting point, the instrumentation employed might be more or less sophisticated. In Figure 2 a scheme of a complete SWE device is shown. For instance, a dynamic extraction might require more accurate pumps in order to maintain a precise flow rate during the whole extraction procedure. Besides, in this case, a heating coil should be included inside the oven so that the water reaches the extraction cell at the set temperature. Although the extraction cell is a simple device, it should be 
Functional Ingredients from Algae for Foods and Nutraceuticals (Cap.16): 534-560 (2013)

doi: 10.1533/9780857098689.3.534 isbn: 978-0-85709-512-1

capable of withstanding high pressures and should include a frit at the exit in order to avoid sample losses. Also, a nitrogen circuit can be included in the system. This circuit can be very useful to purge all the system after the extraction as well as to assure that all the extracting water has reached the collecting vial once the extraction is finished. There are a number of commercial instruments available in the market, although different applications have been also presented with lab-made instruments. In both cases, it has to be considered that given the operating pressures and temperatures usually employed, corrosive-resistant materials have to be used. For further information on how to build your own system, readers are referred to Turner and Ibáñez (2011)

\subsection{Applications to the extraction of bioactive components from algae; comparison with conventional processes.}

As mentioned in the introduction, environmental parameters, such as water temperature, salinity, light and nutrients available can modify the chemical composition of algae and microalgae. For that reason, not only the presence of a particular compound makes algae interesting as source of bioactive compounds but also their huge diversity, the possibility of harvesting or growing at conditions that lead to an enrichment of some bioactives, and the chance of using sophisticated genetic engineering tools able to also produce certain type of compounds (Plaza et al., 2008; Plaza et al., 2009; Johanningmeier and Fischer, 2010; Wijffels, 2008). In the last years several processes have been developed and optimized focused on the extraction of bioactive compounds from algae and microalgae. The composition of those extracts is highly dependent on algae specie, culture and growing conditions and extraction conditions. 
Functional Ingredients from Algae for Foods and Nutraceuticals (Cap.16): 534-560 (2013) doi: 10.1533/9780857098689.3.534 isbn: 978-0-85709-512-1

\subsubsection{Antioxidants}

Interest in natural antioxidants for both health and improved food stabilization has intensified dramatically since the last decade of the XX century. Health applications have been stimulated by observations that free radicals and oxidation are involved in many physiological functions and cause pathological conditions. In fact, the antioxidant capacity has been related to different disease processes and their prevention such as cancer, coronary heart diseases, inflammatory disorders, neurological degeneration, aging, etc. (Madhavi et al., 1996). On the other hand, natural antioxidants offer food, pharmaceutical, nutraceutical, and cosmetic manufacturers a "green" label, minimal regulatory interference with use, and the possibility of multiple actions that improve and extend food and pharmaceutical stabilization (Schaich, 2006).

Several compounds from marine sources have proven their antioxidant activity both, in vitro and in vivo. Among them, phenolic compounds can be appropriately extracted using SWE. Phenols are an important group of natural products with antioxidant and other biological activities. These compounds play an important role in algal cell defense against abiotic and biotic stress. Several authors have recently published results regarding the total phenol content and antioxidant activity of algae (Ganesan et al., 2008). The main bioactivity associated to phenolic compounds is antioxidant activity, which is also the main bioactivity of algal and microalgal phenolics (Kumar et al., 2008).

The content and profile of phenolic substances in marine algae vary with the species. While bromophenols are the main antioxidants in red marine algae (Takamatsu et al., 2003), in marine brown algae, a group of polymers called phlorotannins comprises the major phenolic compounds (Chkikvishvili and Ramazanov, 2000) such as fucols, 
Functional Ingredients from Algae for Foods and Nutraceuticals (Cap.16): 534-560 (2013) doi: 10.1533/9780857098689.3.534 isbn: 978-0-85709-512-1

phlorethols, fucophlorethols, fuhalols and halogenated and sulphited phlorotannins. Some of the first polyphenols found in algae (Fucus and Ascophyllum spp.) were phlorotannins. They are formed from the oligomeric structures of phloroglucinol $(1,3,5-$ trihydroxybenzene) (Parys et al., 2007). Also, some flavanone glycosides have been found even in fresh water algae (Konishi et al., 2003).

Although some references can be found in the literature dealing with polyphenol's extraction using water as a solvent (Wang et al., 2009; López et al., 2011), it seems clear that water by itself at low temperatures is not able to provide with similar results as using for instance, ethanol or acetone as extracting solvents. One possibility of increasing polyphenol's extraction efficiency is the use of enzyme-assistant extraction that consists on an enzymatic step previous or simultaneous to water extraction. In this case, the release of polyphenols from algae cell wall structures by using carbohydrate degrading enzymes and proteases has been suggested, for instance, for extracting polyphenols with antioxidant activity from seven species of brown seaweeds (Heo et al., 2005) or red algae (Wang et al., 2010). A review on the use of enzyme-assistant extraction (EAE) on the recovery of industrially important metabolites from seaweeds has recently been published (Wijesinghe and Jeon, 2012a). Another possibility of increasing polyphenol's extraction from algae is the combined use of enzymatic degradation together with extraction with water at high temperatures. By using this combination it would be possible to improve the release of bioactive compounds and to increase the extraction efficiency by both mechanisms, polyphenols release from cell walls or from protein-algal polyphenol complex, and increase of compound's solubility by increasing water temperature and pressure. Although this combination has not been 
Functional Ingredients from Algae for Foods and Nutraceuticals (Cap.16): 534-560 (2013) doi: 10.1533/9780857098689.3.534 isbn: 978-0-85709-512-1

tested yet in algae, it success in the extraction of valuable compounds from other natural sources such as onion waste, suggest a new use of this approach (Turner et al., 2006). Other compounds found in algae with important antioxidant properties are carotenoids. Haematoccoccus pluvialis is a green microalgae well known by its content in antioxidants belonging to carotenoid class (mainly astaxanthin). H. pluvialis has been evaluated as a source of other kind of antioxidant compounds using subcritical water as extraction agent (Rodríguez-Meizoso et al., 2010). In a previous work by the same authors (Jaime et al., 2010) other solvents were used also in subcritical conditions, such as hexane and ethanol. The effect of the extraction temperature $(50,100,150$, and 200 ${ }^{\circ} \mathrm{C}$ ) and the polarity of the solvent has been estimated in terms of in vitro antioxidant activity. Results in both works demonstrated that the extraction temperature had a positive influence in the extraction yield, although its effect in the antioxidant activity was negative, lowering the activity of the extracts with an increase of the extraction temperature when ethanol and hexane were used as extracting solvents. When using water as solvent, the extraction temperature had a positive influence on the antioxidant activity; in this sense, a possible correlation was found between the antioxidant activity and vitamin E, simple phenols (gallate derivatives), caramelization products, and possible Maillard reaction products obtained during the extraction at high temperatures. Nevertheless, the compounds responsible for this activity in the ethanol and hexane extracts were carotenoids (astaxanthin, lutein, etc.).

Certain cyanobacteria such as Phormidium have also been tested to obtain antioxidant fractions using SWE (Rodríguez-Meizoso et al., 2008). The subcritical extracts were obtained using water, ethanol and hexane. Four different extraction temperatures were tested $\left(50,100,150\right.$, and $\left.200^{\circ} \mathrm{C}\right)$ with $20 \mathrm{~min}$ as extraction time. TEAC assay was used 
Functional Ingredients from Algae for Foods and Nutraceuticals (Cap.16): 534-560 (2013) doi: 10.1533/9780857098689.3.534 isbn: 978-0-85709-512-1

to test antioxidant activity of the extracts. In general, hexane and ethanol extracts showed a higher antioxidant capacity that was mainly attributed to carotenoid compounds. On the other hand, the high antioxidant activity of the $200{ }^{\circ} \mathrm{C}$ water extracts was likely related to the presence of Maillard reaction compounds.

As can be seen, the antioxidant activity of subcritical water extracts from algae obtained at high temperatures can be partially attributed to the formation of Maillard reaction products during the extraction process. The neoformation of antioxidants during SWE has been verified in microalgae (Chlorella vulgaris) and algae (Sargassum vulgare, Sargassum muticum, Porphyra spp., Cystoseira abies-marina, Undaria pinnatifida and Halopitys incurvus) (Plaza et al., 2010a). Results obtained from this study suggested that neoformed compounds derived from Maillard, caramelization and thermoxidation reactions affect the overall antioxidant capacity of water subcritical extracts depending on the nature of the sample. The brown algae $U$. pinnatifida was the sample in which these chemical events contributed positively to a higher extent.

Among other interesting antioxidant compounds extracted using SWE are phycobiliproteins, which are a group of colored proteins commonly present in cyanobacteria and red algae possessing a wide spectrum of applications. The major organisms exploited for production are the cyanobacterium Spirulina for phycocyanin and the red alga Phorphyridium for phycoerythrin (Sekar and Chandramohan, 2008). Beside their antioxidant activity, phycobiliproteins have many other uses such as: pigments, fluorescent dyes, anti-inflammatory, neuroprotective and hepatoprotective activity. Several classical extraction methods have been used, including extraction with distilled water, extraction by homogenization in a mortar and pestle in the presence of acid-washed neutral sand using $50 \mathrm{mM}$ sodium phosphate buffer at $\mathrm{pH} 6.8$, extraction 
Functional Ingredients from Algae for Foods and Nutraceuticals (Cap.16): 534-560 (2013) doi: 10.1533/9780857098689.3.534 isbn: 978-0-85709-512-1

by homogenization in a Virtimixer in $50 \mathrm{mM}$ phosphate buffer at $\mathrm{pH} 6.8$, and extraction with various concentrations of hydrochloric acid ( 2 to $10 \mathrm{~N})$ at room temperature (Sarada et al., 1999). But in 2004 a fast green method was developed using SWE (Herrero et al., 2004). In this work, the use of water for phycobiliprotein's extraction was compared with other solvents (hexane, light petroleum and ethanol) and extracts were characterized by using micellar electrokinetic chromatography with diode array detection (MEKC-DAD). The presence of phycobiliproteins in presurized water extracts was confirmed by using CE-MS (Herrero, et al., 2005; Simó et al., 2005). The optimal conditions to extract phycocyanin from Spirulina were $1500 \mathrm{psi}$ and $25^{\circ} \mathrm{C}$, using glass beads as packing material and 15 min of extraction time.

\subsubsection{Antimicrobials and antivirals}

Besides compounds with antioxidant properties, algae are also a natural source of other compounds with interesting biological activity such as antimicrobials and antivirals, which inhibits the growth or multiplication of microorganisms (Mayer et al., 2009). A large number of algae extract have shown to have antimicrobial activity against microbial species, yeast or fungus (Gupta and Abu-Ghannam, 2011; Caki et al., 2011; Pierre et al., 2011; Khairy and El-Kassas, 2010; Santoyo et al., 2009; Thillairajasekar et al., 2009). However, the antimicrobial activity depends on both algal species and the efficiency of the extraction method. For instance, the diethyl ether extract of $D$. linearis was ineffective against microorganisms, whereas its ethanolic extract showed antimicrobial activity against gram-negative bacteria and Candida sp. This fact is related to the presence of bioactive metabolites which are soluble in ethanol but not in diethyl ether (Tüney et al., 2006). In spite that the most employed methods for 
Functional Ingredients from Algae for Foods and Nutraceuticals (Cap.16): 534-560 (2013) doi: 10.1533/9780857098689.3.534 isbn: 978-0-85709-512-1

extracting compounds with antimicrobial activity from alga are still conventional extraction methods employing organic solvents (ethyl acetate, diethyl ether, chloroform, hexane, methanol, ethanol) or water as extraction solvent, several works have been published in the literature dealing with pressurized liquid extraction of antimicrobial compounds from different algae (Herrero et al., 2006b; Rodríquez-Meizoso et al., 2008; Plaza et al., 2010c; Plaza et al., 2012). In all these works, different solvents (including water), covering a wide range of dielectric constants were tested, allowing the evaluation of the influence of the solvent polarity on the extraction of antimicrobial compounds. The extraction yields obtained using subcritical water extraction followed a different behaviour in each algae studied; the lowest extraction yields (comparing with the other solvents tested) were achieved for Dunaliella salina and Phormidium species (Herrero et al. 2006b; Rodríguez-Meizoso et al. 2008) whereas the highest values were obtained for Himanthalia elongata, Synechocystis sp, and Chlorella vulgaris (Plaza et al. 2010c; Plaza et al. 2012). Regarding the antimicrobial activity of the different extracts obtained in these works, those obtained using water as extraction solvent were the less active against the different microorganisms tested.

Lately, Rodríguez-Meizoso et al (2010) carried out the study of bioactive compounds from Haematococcus pluvialis extracted by SWE (Rodríquez-Meizoso et al., 2010). Using a pretreatment based on three freezing-smashing-thawing cycles (to enhance extraction yields), four different temperatures $\left(50,100,150\right.$, and $\left.200{ }^{\circ} \mathrm{C}\right)$ with $20 \mathrm{~min}$ as extraction time were tested. All the extracts obtained showed a good antimicrobial activity against bacteria and yeast and small antifungal activity against Aspergillus niger. The analysis of the antimicrobial activity as a function of extraction temperature indicated that the temperature did not really affect the extraction of antimicrobial 
Functional Ingredients from Algae for Foods and Nutraceuticals (Cap.16): 534-560 (2013) doi: 10.1533/9780857098689.3.534 isbn: 978-0-85709-512-1

compounds from the algae. In addition, the characterization of these extract by GC-MS demonstrated that short chain fatty acids could be responsible of the observed antimicrobial activity.

The fact that algae may produce antiviral compounds is also well-known since different studies have reported a number of compounds from algae extracts with potent antiviral activity (Iwashima et al., 2005; Rodríguez et al., 2005; De Souza et al., 2005; Lee et al., 2006; Soares et al., 2007; Hayashia et al., 2008; Vo et al., 2011). Water or methanol have been usually employed to screen for antiviral compounds from different algae. However, the antiviral potential of most algae remains unknown since this sort of analysis has been carried out only with few species.

Only a few applications can be found in the literature dealing with the ability of pressurized liquid extraction to obtain antiviral compounds from algae such as Chlorella vulgaris (Santoyo et al., 2010), Himanthalia elongata (Santoyo et al., 2011), Haematococcus pluvialis and Dunaliella salina (Santoyo et al., 2012). Extractions were performed using different solvents (water, ethanol, and hexane or acetone) under subcritical conditions. Namely, when using Haematococcus pluvialis and Himanthalia elongata, extractions were performed at $100{ }^{\circ} \mathrm{C}$ for $20 \mathrm{~min}$, whereas for Chlorella vulgaris and Dunaliella salina, extractions were carried out at $150^{\circ} \mathrm{C}$ for $20 \mathrm{~min}$ and $160{ }^{\circ} \mathrm{C}$ for $15 \mathrm{~min}$, respectively. The antiviral properties of the obtained extracts were evaluated against Herpes simplex virus type 1 (HSV-1). The extracts obtained for all the algae studied were able to inhibit HSV-1 intracellular replication as well as disrupt the step of attachment. Regarding water extracts, a higher antiviral activity was shown by the polysaccharides-rich fraction isolated from these extracts compared to the original 
Functional Ingredients from Algae for Foods and Nutraceuticals (Cap.16): 534-560 (2013)

doi: 10.1533/9780857098689.3.534 isbn: 978-0-85709-512-1

water extract. Therefore, polysaccharides present in water extracts could be suggested as the compounds responsible for the antiviral activity.

\subsubsection{Other bioactive products from algae in the frontier to be extracted}

As mentioned, pressurized liquid extraction, more specifically SWE (or PHWE), is a quite novel extraction process with many interesting applications nowadays. Although this technique has demonstrated its usefulness to obtain bioactive compounds with antioxidant, antimicrobial and antiviral activity form different algae, its possible use as an alternative to conventional extraction methods for some applications has not been demonstrated yet.

In the following sections of the chapter we will study the possibility of using SWE as an alternative to traditional methods for selected applications for which no references have been found. With no doubt, this has to be taken as a possibility since the final usefulness of the technique will need further and serious studies to determine the validity of the process and/or the hypotheses developed and presented in this part. Compounds selected "in the frontier to be extracted" are those that fulfill the requirements for water extraction in terms of high to medium polarity, low basicity and high proticity (Turner and Ibáñez, 2011), that are found in different types of algae and provide with important biological activities; in this sense, carbohydrates, bioactive peptides, neuroprotective compounds, pigments and toxins are discussed.

\subsubsection{Carbohydrates or Saccharides}

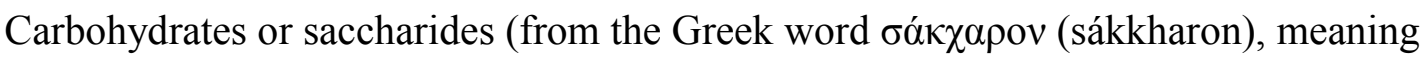
"sugar") are organic compounds with the empirical formula $\mathrm{C}_{\mathrm{m}}\left(\mathrm{H}_{2} \mathrm{O}\right)_{\mathrm{n}}$ (where $\mathrm{m}$ could 
Functional Ingredients from Algae for Foods and Nutraceuticals (Cap.16): 534-560 (2013) doi: 10.1533/9780857098689.3.534 isbn: 978-0-85709-512-1

be different from $\mathrm{n}$ ) highly abundant among marine algae and microalgae. The use of subcritical water to perform integrated processes (extraction, fractionation, reaction...) involving marine carbohydrates could be a future trend to consider. For instance, saccharides have been extracted with subcritical water from non-sea vegetable such as citrus (Tanaka et al., 2012). In fact is in the fractionation step when subcritical water (hydrothermal treatment) could be easily applied to algae and microalgae due to their high content in polysaccarides. Although some information can be found on the hydrothermal processing of agricultural residues, the exact composition of the product streams will be mainly dependent on the starting material (Liu and Wyman, 2003; Pronyk et al., 2011), therefore, there are no possibilities for extrapolating the published results.

On the other hand, polysaccarides from algae have been extensively reviewed and characterized; for instance, during the last three decades, the group of Anatolii Usov, from the Russian Academy of Sciences, published a series of works entitled "Polysaccharides from algae" (Usov et al., 1992; Usov et al., 2001). Among marine polysaccharides, fucoidans and sulfated polysaccharides from brown algae have attracted steady attention in the last few years as readily accessible biopolymers possessing a wide spectrum of biological activities. Fucoidans represent a rather heterogeneous group of polysaccharides in which their simplest representatives contain only $\alpha$-L-fucose, sulfate, and acetate (Usov et al., 2001). It is noteworthy that fucoidans isolated from species belonging to different orders of brown algae can differ in the structure of the main chain: in addition to fucose, they contain xylose, galactose, mannose, and glucuronic acid while other polysaccharides, composed for example, of residues of galactose or glucuronic acid and mannose, in which fucose is only a 
Functional Ingredients from Algae for Foods and Nutraceuticals (Cap.16): 534-560 (2013) doi: 10.1533/9780857098689.3.534 isbn: 978-0-85709-512-1

component of side chains, are also often classified as fucoidans (Jiao et al., 2011).

Figure 3 illustrates the fucoidans structure from Fucus vesiculosus.

Generally polysaccharides from seaweeds have been extracted using water or aqueous organic solvents (Albuquerque et al., 2004), although extraction efficiency will be influenced by the chemical nature of the components, the extraction method employed and the presence of interfering substances (Wijesinghe and Jeon, 2012b). On the other hand, saccharides can be sequentially extracted based on their different solubility. For example, the extraction procedure in the brown seaweed Fucus vesiculosus includes water, acid, and alkali treatments (Rupérez et al., 2002); laminarans (linear polysaccharides, with a $\beta(1 \rightarrow 3): \beta(1 \rightarrow 6)$ ratio of $3: 1)$ are extracted using water, although their solubility depend on the branching level, being higher the solubility at higher branching degree. Fucans are extracted with diluted hydrochloric acid, while alginates are extracted with alkali. Alginates form insoluble precipitates of alginic acid at low $\mathrm{pH}$, but they are stable in solution between $\mathrm{pH} 6$ and 9.

On the other hand, sulfated galactans from red seaweeds are soluble in aqueous solution at $20{ }^{\circ} \mathrm{C}$, while those less modified such as agar in Nori (Porphyra spp.) are soluble at 60-80 ${ }^{\circ} \mathrm{C}$ (Rupérez and Toledano, 2003). As could be seen, pressurized water could be used to extract algal saccharides, both alone and in combination with acids or alkalis. However, as mentioned previously for polyphenols' extraction, since the cell wall consists of complex polymers, it is not easy to extract active polysaccharides using a conventional solvent extraction process. The production of different bioactive polysaccharides using an enzyme-assisted extraction with lyases increases the extraction efficiency of the process (Wijesinghe and Jeon, 2012b). In this sense SWE could be an interesting alternative to isolate algal polysaccharides since it could be used alone or in 
Functional Ingredients from Algae for Foods and Nutraceuticals (Cap.16): 534-560 (2013)

doi: 10.1533/9780857098689.3.534 isbn: 978-0-85709-512-1

combination with an enzymatic treatment inside the extraction vessel. In addition, the dissociation constant of subcritical water for hydrogen and hydroxyl ions is three orders of magnitude higher than that of ambient water; consequently, subcritical water can act as an acid or an alkali (Wiboonsirikul and Adachi, 2008). This potential has been exploited to extract and hydrolyze polysaccharides from other sources (Sasaki et al., 2000).

\subsubsection{Bioactive peptides}

Many studies have reported that peptides from various food sources possess bioactivities, including antihypertensive, antioxidant, anticancer, antimicrobial, and opioid activities as well as immunomodulatory and cholesterol-lowering effects (Shahidi and Zhong, 2008). The primary structure of natural proteins consists of certain amino acid sequences that have the ability to exert physiological benefits in human beings. When the parent protein is acted upon by an appropriate enzyme (usually a protease), the peptide is released. When consumed as pure peptides or more likely as ahydrolysate, the active peptides must survive digestion as they pass through the gastrointestinal tract and must be absorbed intact into the blood circulatory system. The peptides are then transported to various organs and tissues where they modulate the structure and function of metabolic enzymes that participate in the pathogenesis of chronic diseases.

Recently, great interest has been expressed regarding marine-derived bioactive peptides because of their numerous health benefits. In addition, many studies have been reported that marine bioactive peptides can be used as functional foods, nutraceuticals, or pharmaceuticals due to their therapeutic potential in the treatment or prevention of 
Functional Ingredients from Algae for Foods and Nutraceuticals (Cap.16): 534-560 (2013) doi: 10.1533/9780857098689.3.534 isbn: 978-0-85709-512-1

various diseases (Kim and Kang, 2011). Arthrospira (Spirulina), Chlorella, and D. salina were used in human nutrition diets because of their high protein content and their excellent nutritive value, therefore this high protein content can be used as a source of bioactive peptides.

Anticancer peptides have attracted attention recently due to their characteristic features such as multifunction, high sensitivity, and stability. Just few studies have been reported about microalgae protein as a source of anticancer peptides (Kim and Kang, 2011), but there are a quite large number of publications on anticancer peptides from food protein from several sources (Udenigwe and Aluko, 2012). However, recent studies suggest that the microalgae-derived peptides could be potentially useful adjuncts in the treatment of gastric cancer (Sheih et al., 2010). Therefore, this can be a potential protein source for the future industrial production of functional peptides.

The angiotensin I-converting enzyme (ACE) participates in regulating blood pressure in the renin-angiotensin system. The ACE-inhibitory activity of various source have studied, and it was found that some ACE-inhibitory peptides were produced by enzymatic digestion of various marine food proteins (Kim and Kang, 2011). However, to date, scarce work of the potential ACE-inhibitory compounds such as biopeptides from seaweeds has been done. The main studied algae for this purpose has been wakame (Undaria pinnatifida) (Sato et al., 2002; Suetsuna and Nakano, 2000), whose bioactive peptides from protease digestion have been isolated using solvents such as butanol and column elution with acidified water. Since bioactive peptides are water soluble, they could also be extracted using one step of an integrated procedure combining enzyme-assisted extraction (EAE) and SWE. 
Functional Ingredients from Algae for Foods and Nutraceuticals (Cap.16): 534-560 (2013)

doi: 10.1533/9780857098689.3.534 isbn: 978-0-85709-512-1

\subsubsection{Neuroprotective compounds}

Alzheimer's disease (AD) is an irreversible, progressive neurodegenerative disease, which results in memory loss, behavior disturbances, personality changes and a decline in cognitive abilities. It was stated in the cholinergic hypothesis, that a serious loss of cholinergic function in the central nervous system (CNS) contributes significantly to the cognitive symptoms associated with AD. The inhibition of acetylcholinesterase (AChE) enzyme, which catalyzes the breakdown of the neurotransmitter acetylcholine (ACh), may be one of the most realistic approaches to the symptomatic treatment of AD (Tabet, 2006). Otherwise, the use of synthetic AChE inhibitors is under study due to their secondary effects associated with the requirement to be used for long term or indefinitely (depleting neurotransmitter substrate, altering tone of surviving neurons, or just having no effect) (Schneider, 2012). This fact reveals the need of finding new sources of compounds that interact with the cholinergic function.

A number of studies have recently shown AChE inhibitory activity of several marine algae species, such as Ecklonia stolonifera, Ishige okamurae, Caulerpa racemosa, Ulva, Amphiora or Hypnea valentiae (Pangestuti and Kim, 2011a). The main neuroprotective compounds found in algae belong to two families of compounds: sterols and phlorotannins. Most of those bioactivities have been proven using room temperature methanol or ethanol extraction (Stirk et al., 2007; Suganthy et al., 2010; Cho et al., 2012). Therefore in both cases, extractions could be performed using subcritical water, because their extraction could be mediated by the change in polarity (dielectric constant) of water with temperature close to critical point. In addition, a substantial increase in the ionic product during subcritical water extraction, in particular, at temperatures between 120 and $250^{\circ} \mathrm{C}$, contributes to the hydrolysis which enhances the 
Functional Ingredients from Algae for Foods and Nutraceuticals (Cap.16): 534-560 (2013)

doi: 10.1533/9780857098689.3.534 isbn: 978-0-85709-512-1

mass transfer, like the decreasing in the viscosity and surface tension close to the critical point (Wiboonsirikul and Adachi, 2008).

\subsubsection{Pigments}

Among functional ingredients from algae, pigments have received particular attention. Besides their photosyntethic and pigmentation effects, these pigments exhibit different health benefit, such as antioxidant, anticancer, anti-inflammatory (Pangestuti and Kim, 2011b). Carotenoids, chlorophylls and phycobiliproteins are the basic classes of pigments that can be found in algae. According to the pigment content, algae can be classified into brown (Phaeophycea), red (Rhodophyta) and green (Chlorophyta) algae. Carotenoids are lipid-soluble compounds consisting of long, aliphatic and conjugated doubled-bonded system usually composed of eight isoprene units (Cha et al., 2008). They can be classified into two types; hydrocarbon carotenoids which are known as carotenes, and oxygenated derivatives named as xanthopylls in which oxygen can be present as $\mathrm{OH}$ group (lutein), oxi-groups (cantaxanthin) or in combination of both (astaxanthin, fucoxanthin) (Guedes et al., 2011; Del Campo et al., 2007). Chlorophylls are also lipid-soluble pigments which contain a porphyrin ring. The main types of chlorophylls are chlorophyll a and chlorophyll $\mathrm{b}$, however the sensitivity of these pigments to $\mathrm{pH}$ and temperature results in the formation of numerous degradation products such as pheopytins, pyropheophytins, etc. (Pangestuti and Kim 2011b; Hosikian et al., 2010). Due to the lipid-soluble character of both carotenoids and chlorophylls, their extraction has been carried out mainly using organic solvents (acetone, ethanol, hexane) in traditional extraction approaches (Simon and Helliwell, 1998; Domínguez-Bocanegra et al., 2004; Orosa et al., 2005; Van Leeuwe et al., 2006; 
Functional Ingredients from Algae for Foods and Nutraceuticals (Cap.16): 534-560 (2013) doi: 10.1533/9780857098689.3.534 isbn: 978-0-85709-512-1

Sarada et al., 2006; Cha et al., 2008) or under pressurized liquid extraction conditions (Denery et al., 2004; Jaime et al, 2010). Besides, several works have used a small percentage of water in combination with the main extraction solvent $(90 \%$ ethanol/water) to carry out the pressurized liquid extraction of carotenoids and chlorophylls from green algae (Chlorella vulgaris) (Cha et al., 2010a; Cha et al., 2010b), or fucoxanthin, which is widely distributed in nature (its contribution to the estimated production of carotenoid in nature is about $10 \%$ ) and is the principal pigment in brown seaweed (Shang et al., 2011). SWE has been also employed as alternative extraction procedure for obtaining bioactive compounds (carotenoids and chlorophylls between them) from Haematococcus pluvialis (Rodríguez-Meizoso et al., 2010) and chlorella vulgaris (Plaza et al., 2012). However, no significant amounts of carotenoids and chlorophylls were obtained in the water extract, mainly due to the non-polar nature of these compounds.

Finally, phycobiliproteins, the others pigments found in algae, can be classified in phycocyanins, allophycocyanins and phycoerythtins, being the latter the most abundant in many red algae (Pangestuti and Kim, 2011b). Since phycobiliproteins are water soluble, they can be extracted by SWE; in fact, different works (see section 17.4.1) have demonstrated the presence of these compounds in pressurized water extracts from algae (Herrero et al., 2004, Herrero, et al., 2005; Simó et al., 2005).

\subsubsection{Therapeutic and pharmacologic products}

Certain species of marine microalgae are able to produce potent toxins, which can be accumulating in filter-feeding shellfish and lead to poisoning fish marine mammals, sea 
Functional Ingredients from Algae for Foods and Nutraceuticals (Cap.16): 534-560 (2013) doi: 10.1533/9780857098689.3.534 isbn: 978-0-85709-512-1

birds and humans. Some of these toxins, on the other hand, have been suggested as potent anticancer drugs or even as anaesthetic agents.

During the past two decades, a variety of toxins from algae and cyanobacteria have been identified (Dahlmann et al., 2003). According to their chemical structure, toxins may be classified into three main groups: cyclic peptides (microcystins and nodularins), alkaloids (neurotoxins and cylindrospermopsin), and lipopolysaccharides (Msagati et al., 2006).

The chemical structures of toxins are complex and although a high number of them are lipophilic (brevetoxins or okadaic acid), others, for instance domoic acid or saxitoxins, present hydrophilic properties (Pistocchi et al., 2012; Gerssen et al., 2010).

Some reports have shown important pharmacological properties of, for instance, paralytic shellfish toxins such as saxitoxin and neosaxitoxin, which are potent nonprotein neurotoxins which have been studied as potent local (Rodríguez-Navarro et al., 2007) and long term anaesthetic agents (Hille, 1975; Adams et al., 1976); their activity seems related to a selective and reversible blockage of the voltage-gated sodium channels at the neuronal level. For further information on the different structures of neurotoxins, their toxicity and possible biotransformations, readers are referred to a recent publication (Wiese et al., 2010).

On the other hand, other recent studies have suggested the use of microcystins (potent hepatotoxins) as a novel class of anticancer agent. Results from this study showed that microcystin-induced phosphatase inhibition results in potent hepato-cytotoxicity when microcystin compounds can gain intracellular access (Monks et al., 2007).

The solvents employed to extract these toxins include $5 \%$ acetic acid, methanol, acidified methanol, water and mixtures methanol:water (Lawton and Edwards, 2001; 
Functional Ingredients from Algae for Foods and Nutraceuticals (Cap.16): 534-560 (2013)

doi: 10.1533/9780857098689.3.534 isbn: 978-0-85709-512-1

Lawrence and Menard, 2001; McElhiney and Lawton, 2005). Mixtures of methanol:water have been also used as solvent to extract various algal and cyanobacterial toxins (saxitoxin, anatoxin-a, domoic acid, nodularin, microcystins, okadaic acid and dinophysissistoxin-1) from phytoplankton (Dahlmann et al., 2003) and aqueous $5 \%$ formic acid was employed to the extraction of cylindrospermopsin for the analysis of blue-green algal food supplements (Liu and Scott 2011). Taking into account that dielectric constant of water at high temperatures is similar to that presented by some organic solvents, such as methanol (Wiboonsirikul and Adachi , 2008), SWE could be potentially be employed as an alternative to solvent extraction of different toxins. In this sense, Aranda-Rodríguez et al. (2005) demonstrated the suitability of PLE and SWE for extracting toxins from Microcystis aeruginosa cyanobacterial cells. The results obtained in this work, suggest that water at high pressure and temperature $\left(60-100{ }^{\circ} \mathrm{C}\right)$, can be a good solvent for the extraction of microcystins with a wide range of polarity.

\subsection{Future trends and conclusions.}

As can be inferred from the data shown above, one of the future trends in the use and applications of SWE (PHWE) is the development of green integrated systems able to perform multi-unit operations such as reaction, extraction, fractionation, etc. Subcritical water extraction can be used in some or all the mentioned operations with some advantages over conventional processes; on the other hand, it can be easily combined with other green solvents such as sub- or supercritical carbon dioxide or ethanol. Related to this, a clear trend is the use of PHWE together with enzymatic catalysis that is, transforming the actual enzyme-assistant-extraction (EAE) to a subcritical water 
Functional Ingredients from Algae for Foods and Nutraceuticals (Cap.16): 534-560 (2013) doi: 10.1533/9780857098689.3.534 isbn: 978-0-85709-512-1

enzymatic reaction and extraction (SWERE). Although just few examples can been found in the literature by using this approach, it seems clear that by the development of new and thermostable enzymes and new approaches for extracts' fractionation and purification, the development of this technique can be a reality; as already shown in the pioneer work of Turner (Turner et al., 2006; Lindahl et al., 2010), the environmental impact of the developed method using beta-glucosidase and subcritical water extraction is lower in terms of primary energy consumption and global warming potential as compared to a conventional extraction/hydrolysis method based on methanol extraction and hydrochloric acid hydrolysis at $80 \mathrm{C}$. Considering the wide range of compounds that can be extracted from algae and, at the same time can benefit from the development of integrated processes, it is easy to understand the need of more research in this area; therefore, new ideas and new approaches are expected with the final goal of simplifying, increasing the efficiency and decreasing the risks for the environment and human health. Sustainability will be the target to provide with new answers the challenges we are facing today.

In terms of applications, in this chapter we have tried to provide with an overview of not only the real applications that can be found in the literature in terms of SWE of bioactive compounds from algae (quite scarce nowadays), but also of the different possibilities that the technique offers for the extraction of other valuable compounds (such as peptides, carbohydrates, pigments, compounds with therapeutic properties, etc.) that, even if they have not been approached that way, the use of subcritical water extraction may provide with some advantages over the conventional processes used, at least in terms of efficiency, speed, selectivity, etc. 
Functional Ingredients from Algae for Foods and Nutraceuticals (Cap.16): 534-560 (2013) doi: 10.1533/9780857098689.3.534 isbn: 978-0-85709-512-1

To conclude, water is the greenest solvent in nature and has the potential to replace environmentally burdensome solvents such as acetonitrile, methanol, dichloromethane and toluene at high pressures and temperature. Water can be quite selective by changing the extraction temperature, and processes are quite easy to optimize towards the enrichment of the compound/s of interest; on the other hand, it is important to consider that care must be taken with thermolabile compounds' extraction, although risks can be minimized by a careful optimization of extraction time and temperature. With all these considerations we can conclude that SWE (or PHWE) can be an appropriate choice for many applications requiring a medium to high polarity solvent and for compounds with some degree of polarizability; in those cases, the process can give many advantages that, at the end, can lead to a more efficient, environmentally friendly and sustainable extraction process.

\subsection{References.}

Adams HJ, Blair MR Jr, Takman BH (1976), The local anesthetic activity of saxitoxin alone and with vasoconstrictor and local anesthetic agents, Arch Int Pharmacodyn Ther, $224,275-282$.

Albuquerque IRL, Queiroz KCS, Alves LG, Santos EA, Leite EL, Rocha HAO (2004) Hetarofucans from Dictyota menstrualis have anticoagulant activity.Brazilian, $J$ Med Biol Res, 37, 167-171. 
Functional Ingredients from Algae for Foods and Nutraceuticals (Cap.16): 534-560 (2013) doi: 10.1533/9780857098689.3.534 isbn: 978-0-85709-512-1

Aranda-Rodríguez R, Tillmanns A, Benoit FM, Pick FR, Harvie J, Solenaia L (2005), Pressurized liquid extraction of toxins from cyanobacterial cells, Environ Tox, 20, 390396.

Caki Z, Öztiirk M, Taskin E, Taskin E (2011), Antioxidative and antimicrobial activities of some marine algae, Fresenius Environ Bull, 20, 1001-1006.

Cha KH, Koo SY, Lee DU (2008), Antiproliferative effects of carotenoids extracted from chlorella ellipsoidea and chlorella vulgaris on human colon cancer cells, J. Agric Food Chem, 56, 10521-10526.

Cha KH, Lee HJ, Koo SY, Song DG, Lee DU, Pan CH (2010a) Optimization of pressurized liquid extraction of carotenoids and chlorophylls from chlorella vulgaris, $J$ Agr Food Chem, 58, 793-797.

Cha KH, Kang SW, Kim CY, Um BH, Na YR, Pan CH, (2010b) Effect of pressurized liquids on extraction of antioxidants from chlorella vulgaris, J Agr Food Chem, 58, $4756-4761$

Chkikvishvili ID, Ramazanov ZM (2000), Phenolic substances of brown algae and their antioxidant activity, Appl Biochem Microbiol, 36, 289-291.

Cho S, Yang H, Jeon YJ, Lee CJ, Jin YH, Baek NI, Kim D, Kang SM, Yoon M, Shimizu M, Han D (2012), Phlorotannins of the edible brown seaweed Ecklonia cava Kjellman induce sleep via positive allosteric modulation of gamma-aminobutyric acid type A-benzodiazepine receptor, Food Chem, 132, 1133-1142.

Dahlmann J, Budakowski WR, Luckas B (2003), Liquid chromatography-electrospray ionisation-mass spectrometry based method for the simultaneous determination of algal 
Functional Ingredients from Algae for Foods and Nutraceuticals (Cap.16): 534-560 (2013) doi: 10.1533/9780857098689.3.534 isbn: 978-0-85709-512-1

and cyanobacterial toxins in phytoplankton from marine waters and lakes followed by tentative structural elucidation of microcystins, J Chromatogr A, 994, 45-57.

Day JG, Slocombe SP, Stanley MS (2012), Overcoming biological constraints to enable the exploitation of microalgae for biofuels, Bioresour Technol, 109, 245-251.

De Souza PH, Leao-Ferreira LR, Moussatche N, Teixeira VL, Cavalcanti DN, da Costa LJ, Diaz R, Frugulhetti IC (2005), Effects of diterpenes isolated from the Brazilian marine alga Dictyota menstrualis on HIV-1 reverse transcriptase, Planta Med, 71, 10191024.

Del Campo JA, García-González M, Guerrero MG (2007), Outdoor cultivation of microalgae for carotenoid production: current state and perspectives, Appl Microbiol Biotechnol, 74, 1163-1174.

Denery JR, Dragull K, Tang CS, Li QX (2004), Pressurized fluid extraction of carotenoids from haematococcus pluvialis and dunaliella salina and Kavalactones from Piper methysticum, Anal Chim Acta, 501, 174-181

Domínguez-Bocanegra AR, Guerrero Legarreta I, Martínez Jeronimo F, Tomasini Campocosio A (2004), Influence of environmental and nutritional factor in the production of astaxanthin from Haematococcus pluvialis, Bioresour Technol, 92, 209214.

Ganesan P, Kumar CS, Bhaskar N (2008), Antioxidant properties of methanol extract and its solvent fractions obtained from selected Indian red seaweeds, Bioresource Technol, 99, 2717-2723. 
Functional Ingredients from Algae for Foods and Nutraceuticals (Cap.16): 534-560 (2013) doi: 10.1533/9780857098689.3.534 isbn: 978-0-85709-512-1

Gerssen A, Pol-Hofstad IE, Poelman M, Mulder PPJ, Van den Top HJ, de Boer J (2010), Marine toxins: Chemistry, toxicity, occurrence and detection with special reference to the Dutch situation, Toxins, 2, 878-904.

Guedes AC, Amaro HM, Malcata FX (2011), Microalgae as sources of carotenoids, Mar Drugs, 9, 625-644.

Gupta S, Abu-Ghannam N (2011), Recent developments in the application of seaweeds or seaweed extract as a means for enhancing the safety and quality attributes of foods, Inn Food Sci Emerg Techn, 12, 600-609.

Hayashia K, Nakano T, Hashimoto M, Kanekiyo K, Hayashi T (2008), Defensive effects of a fucoidan from brown alga Undaria pinnatifida against herpes simplex virus infection, Int Immunopharmacol, 8,109-106.

Heo SJ, Park EJ, Lee KW, Jeon YJ (2005), Antioxidant activities of enzymatic extracts from brown seaweeds, Bioresour Technol, 96, 1613-1623.

Herrero, M., Ibáñez, E., Señoráns, J., Cifuentes, A. (2004), Pressurized liquid extracts from Spirulina platensis microalga: Determination of their antioxidant activity and preliminary analysis by micellar electrokinetic chromatography, J Chromatogr A, 1047, 195-203.

Herrero M, Simo C, Ibañez E, Cifuentes A (2005), Capillary electrophoresis-mass spectrometry of Spirulina platensis obtained by pressurized liquid extraction, Electrophoresis, 26, 4215-4224. 
Functional Ingredients from Algae for Foods and Nutraceuticals (Cap.16): 534-560 (2013) doi: 10.1533/9780857098689.3.534 isbn: 978-0-85709-512-1

Herrero M, Cifuentes A, Ibañez E (2006a), Sub- and supercritical fluid extraction of functional ingredients from different natural sources: plants, food-by-products, algae and microalgae - A review, Food Chem, 98,136-148.

Herrero M, Ibáñez E, Cifuentes A, Reglero G, Santoyo S (2006b), Dunaliella salina microalga pressurized liquid extracts as potential antimicrobials, J. Food Protec, 69, 2471-2477.

Hille B (1975), The receptor for tetrodotoxin and saxitoxin. A structural hypothesis. Biophys J, 15, 615-619.

Hosikian A, Lim S, Halim R, Danquah MK (2010), Chlorophyll Extraction from microalgae: A review on the process engineering aspects, Int J Chem Eng, Ariticle ID 391632.

Imhoff JF, Labes A, Wiese J (2011), Bio-mining the microbial treasures of the ocean: New natural products, Biotechnol Adv, 29, 468-482.

Iwashima M, Mori J, Ting X, Matsunaga T, Hayashi K, Shinhoda D, Saito H, Sankawa U, Hayashi T (2005), Antioxidant and antiviral activity of plastoquinones from the brown alga Sargassum micracanthum and a new derivative concerted from the plastoquinones, Biol Pharm Bull, 28, 374-377.

Jaime, L., Rodríguez-Meizoso, I., Cifuentes, A., Santoyo, S., Suarez, S., Ibáñez, E., Señorans, F.J. (2010), Pressurized liquids as an alternative process to antioxidant carotenoids' extraction from Haematococcus pluvialis microalgae, LWT - Food Sci Techn, 43, 105-112. 
Functional Ingredients from Algae for Foods and Nutraceuticals (Cap.16): 534-560 (2013)

doi: 10.1533/9780857098689.3.534 isbn: 978-0-85709-512-1

Javed F, Qadir MI, Janbaz KH, Ali M (2011), Novel drugs from marine microorganisms, Crit Rev Microbiol, 37, 245-249.

Jiao G, Yu G, Zhang J (2011), Chemical structures and bioactivities of sulfated polysaccharides from marine algae, Marine Drugs, 9, 196-223.

Johanningmeier U, Fischer D (2010), Perspective for the use of genetic transformants in order to enhance the synthesis of the desired metabolites: Engineering chloroplasts of microalgae for the production of bioactive compounds, Adv Exp Med Biol, 698, 144151.

Khairy HM, El-Kassas HY (2010), Active substance from some blue green algal species used as antimicrobial agents, Afr J Biotechnol, 19, 2789-2800.

Kim SK, Kang KH (2011) Medicinal effects of peptides from marine microalgae. $A d v$ Food Nutr Res, 64, 313-323.

Konishi T, Yamazoe K, Kanzato M, Konoshima T, Fujiwara Y (2003), Three diterpenoids (excoecarins V1-V3) and a flavanone glycoside from the fresh stem of Excoecaria agallocha, Chem Pharm Bull, 51, 1142-1146.

Kumar CS, Ganesan P, Suresh PV, Bhaskar N (2008), Seaweeds as a source of nutritionally beneficial compounds - A review, J Food Sci Technol, 45, 1-13.

Lawrence JF, Menard C (2001), Determination of microcystins in blue-green algae, fish and water using liquid chromatography with ultraviolet detection after sample clean-up employing immunoaffinity chromatography, J Chromatogr A, 922, 111-117. 
Functional Ingredients from Algae for Foods and Nutraceuticals (Cap.16): 534-560 (2013) doi: 10.1533/9780857098689.3.534 isbn: 978-0-85709-512-1

Lawton LA, Edwards C (2001), Purification of microcystins, J Chromatogr A, 912, 191-209.

Lee JB, Hayaski K, Hirata M, Kuroda E, Suzuki E, Kubo Y, Hayaski T (2006) Antiviral sulfated polysaccharide from Navicula directa, a diatom collected from deep-sea water in Toyama bay, Biol Pharm Bull, 29, 2135-2139.

Li YX, Kim SK (2011) Utilization of seaweed derived ingredients as potential antioxidants and functional ingredients in the food industry: An overview, Food Sci Biotechnol, 20, 1461-1466.

Lindahl S, Ekman A, Khan S, Wennerberg C, Borjesson P, Sjoberg PJR, Karlsson EN, Turner C (2010), Exploring the possibility of using a thermostable mutant of betaglucosidase for rapid hydrolysis of quercetin glucosides in hot water, Green Chem, 12, $159-68$.

Liu C, Wyman CE (2003), The effect of flow rate of compressed hot water on xylan, lignin, and total mass removal from corn stover, Ind Eng Chem Res, 42, 5409-5416.

Liu H, Scott PM (2011), Determination of the cyanobacterial toxin cylindrospermopsin in algal food supplements, Food Addit Contam, 28, 786-790.

López A, Rico M, Rivero A, Suárez de Tangil M (2011), The effects of solvents on the phenolic contents and antioxidant activity of Stypocaulon scoparium algae extracts, Food Chem, 125, 1104-1109.

Madhavi DV, Despande SS, Salunkhe DK (1996), Food antioxidants. New York, Marcel Dekker. 
Functional Ingredients from Algae for Foods and Nutraceuticals (Cap.16): 534-560 (2013)

doi: 10.1533/9780857098689.3.534 isbn: 978-0-85709-512-1

Mayer AMS, Rodríguez AD, Berlinck RBS, Hamann MT (2009), Marine pharmacology in 2005-6: Marine compounds with anthelmintic, antibacterial, anticoagulant, antifungal, anti-inflammatory, antimalarial, antiprotozoal, antituberculosis, and antiviral activities; affecting the cardiovascular, immune and nervous systems, and other miscellaneous mechanisms of action, Biochim Biophys Acta, 1790, 283-308.

McElhiney J, Lawton LA (2005), Detection of the cyanobacterial hepatotoxins microcystins, Tox Appl Pharm, 203, 219-230.

Mendiola JA, Herrero M, Cifuentes A, Ibañez E (2007), Use of compressed fluids for sample preparation: Food applications, J Chromatogr A, 1152, 234-246.

Monks NR, Liu S, Xu Y, Yu H, Bendelow A, Moscow JA (2007), Potent cytotoxicity of the phosphatase inhibitor microcystin LR and microcystin analogues in OATP1B1- and OATP1B3-expressing HeLa cells, Mol Cancer Ther, 6,587-598.

Msagati, TAM, Siame BA, Shushu DD (2006), Evaluation of methods for the isolation, detection and quantification of cyanobacterial hepatotoxins, Aquatic Tox ,78, 382-397.

Ong ES, Cheong JSH, Goh D (2006), Pressurized hot water extraction of bioactive or market compounds in botanicals and medicinal plant materials, J Chromatogr A, 1112, 92-102.

Orosa M, Franqueira D, Cid A, Abalde J (2005), Analysis and enhancement of astaxanthin accumulation in Haematococcus pluvialis, Bioresour Technol, 96, 373-378.

Pangestuti R, Kim SK (2011a), Neuroprotective effects of marine algae, Marine Drugs, 9, 803-818. 
Functional Ingredients from Algae for Foods and Nutraceuticals (Cap.16): 534-560 (2013) doi: 10.1533/9780857098689.3.534 isbn: 978-0-85709-512-1

Pangestuti R, Kim SK (2011b), Biological activities and health benefit effects of natural pigments derived from marine algae, J Functional Foods, 3, 255-266.

Parys S, Rosenbaum A, Kehraus S, Reher G, Glombitza KW, König GM (2007), Evaluation of Quantitative Methods for the Determination of Polyphenols in Algal Extracts, J Nat Prod, 70, 1865-1870.

Pierre G, Sopena V, Juin C, Mastouri A, Graber M, Maugard T (2011), Antibacterial activity of a sulfated galactan extracted from the marine alga Chaetomorpha aerea against Staphylococcus aureus, Biotechnol Bioprocess Eng, 16, 937-945.

Pistocchi R, Guerrini F, Pezzolesi L, Riccardi M, Vanucci S, Ciminiello P, Dell'Aversano C, Forino M, Fattorusso E, Tartaglione L, Milandri A, Pompei M, Cangini M, Pigozzi S, Riccardi E (2012), Toxin levels and profiles in microalgae from the North-Western Adriatic Sea-15 years of studies on cultured species, Mar Drugs, 10, $140-462$.

Plaza M, Cifuentes A, Ibáñez E (2008), In the search of new functional food ingredients from algae, Trends Food Sci Techn, 19, 31-39.

Plaza M, Herrero M, Cifuentes A, Ibáñez E (2009), Innovative natural functional ingredients from microalgae, J Agric Food Chem, 57, 7159-7170.

Plaza M, Amigo-Benavent M, del Castillo MD, Ibáñez E, Herrero M (2010a), Facts about the formation of new antioxidants in natural samples after subcritical water extraction, Food Res Int 43, 2341-2348. 
Functional Ingredients from Algae for Foods and Nutraceuticals (Cap.16): 534-560 (2013)

doi: 10.1533/9780857098689.3.534 isbn: 978-0-85709-512-1

Plaza M, Amigo-Benavent M, del Castillo MD, Ibáñez E, Herrero M (2010b),

Neoformation of antioxidants in glycation model systems treated under subcritical water extraction conditions, Food Res Int, 43, 1123-1129.

Plaza M, Santoyo S, Jaime L, García-Blairsy Reina G, Herrero M, Señoráns FJ, Ibáñez E (2010c), Screening for bioactive compounds from algae, J Pharm Biomed Anal, 51, $450-455$.

Plaza M, Santoyo S, Jaime L, Avalo B, Cifuentes A, Reglero G, García-Blairsy Reina G, Señoráns FJ, Ibáñez E (2012), Comprehensive characterization of the functional activities of pressurized liquid and ultrasound-assisted extracts from Chlorella Vulgaris, LWT-Food Sci Techn, 46, 245-253.

Pronyk C, Mazza G, Tamaki Y (2011), Production of Carbohydrates, Lignins, and Minor Components from Triticale Straw by Hydrothermal Treatment, J Agric Food Chem, 59, 3788-3796.

Rangsriwong P, Rangkadilok N, Satayavivad J, Goto M, Shotipruk A (2009),

Subcritical water extraction of polyphenolic compounds from Terminalia chebula Retz. Fruits, Sep Purif Technol, 66, 51-56.

Rodríguez MC, Merino ER, Pujol CA, Damonte EB, Cerezo AS, Matulewicz MC (2005) Galactans from cystocarpic plants of the red seaweed Callophyllis variegata (Kallymeniaceae, Gigartinales), Carbohydr Res, 340, 2742-2751.

Rodríguez-Meizoso I, Marin FR, Herrero M, Señorans FJ, Reglero G, Cifuentes A, Ibañez E (2006), Subcritical water extraction of nutraceuticals with antioxidant activity 
Functional Ingredients from Algae for Foods and Nutraceuticals (Cap.16): 534-560 (2013) doi: 10.1533/9780857098689.3.534 isbn: 978-0-85709-512-1

from oregano. Chemical and functional characterization. J Pharm Biomed Anal, 41, $1560-1565$.

Rodríguez-Meizoso, I., Jaime, L., Santoyo, S., Cifuentes, A., García-Blairsy Reina, G., Señoráns, F.J., Ibáñez, E. (2008), Pressurized fluid extraction of bioactive compounds from Phormidium species, J Agric Food Chem, 56, 3517-3523.

Rodríguez-Meizoso, I., Jaime, L., Santoyo, S., Señoráns, F.J., Cifuentes, A., Ibáñez, E. (2010), Subcritical water extraction and characterization of bioactive compounds from Haematococcus pluvialis microalga, J. Pharm Biomed Anal, 51, 456-463.

Rodríguez-Navarro AJ, Lagos N, Lagos M, Braghetto I, Csendes A, Hamilton J, Figueroa C, Truan D, García C, Rojas A, Iglesias V, Brunet L, Álvarez F (2007), Neosaxitoxin as a Local Anesthetic. Preliminary Observations from a First Human Trial, Anesthesiology, 106,339-45.

Rupérez P, Ahrazem O, Leal JA (2002), Potential antioxidant capacity of sulfated polysaccharides from the edible marine brown seaweed Fucus vesiculosus, J Agric Food Chem, 4, 840-845.

Rupérez P, Toledano G (2003), Indigestible fraction of edible marine seaweeds, $J$ Sci Food Agric, 12, 1267-1272.

Santoyo S, Rodríguez-Meizoso I, Cifuentes A, Jaime L, García-Blairsy Reina G, Señoráns FJ, Ibáñez E (2009), Green processes base on the extraction with pressurized fluids to obtain potent antimicrobials from Haematococcus pluvialis microalgae, $L W T$ Food Sci Techn, 42, 1213-1218. 
Functional Ingredients from Algae for Foods and Nutraceuticals (Cap.16): 534-560 (2013) doi: 10.1533/9780857098689.3.534 isbn: 978-0-85709-512-1

Santoyo S, Plaza M, Jaime L, Ibáñez E, Reglero G, Señoráns FJ (2010), Pressurized liquid extraction as an alternative process to obtain antiviral agents from edible microalga Chlorella vulgaris, J Agri Food Chem, 58, 8522-8527.

Santoyo S, Plaza M, Jaime L, Ibáñez E, Reglero G, Señoráns FJ (2011), Pressurized liquid as an alternative green process to extract antiviral agents from edible seaweed Himanthalia elongata, J Appl Phycol, 23, 909-917.

Santoyo S, Jaime L, Plaza M, Herrero M, Rodríguez-Meizoso I, Ibáñez E, Reglero G (2012), Antiviral compounds obtained from microalgae commonly used as carotenoids sources, J Appl Phycol, In press (DOI 10.10077s10811-011-9692-1).

Sarada R, Pillai MG, Ravishankar A (1999), Phycocyanin from Spirulina sp. influence of processing of biomass an phycocyanin yield, analysis of efficacy of extraction methods and stability studies on phycocyanin, Process Biochem, 24, 795-801.

Sarada R, Vidhyavathi R, Usha D, Ravishankar GA (2006), An efficient method for extraction of asthaxanthin from green alga haematococcus pluvialis, J Agric Food Chem, 54, 7585-7588.

Sasaki M, Fang Z, Fukushima Y, Adschiri T, Arai K (2000), Dissolution and hydrolysis of cellulose in subcritical and supercritical water, Ind Eng Chem Res, 39, 2883-2890.

Sato M, Hosokawa T, Yamaguchi T, Nakano T, Muramoto K, Kahara T, Funayama K, Kobayashi A, Nakano T (2002), Angiotensin I-converting enzyme inhibitory peptides derived from Wakame (Undaria pinnatifida) and their antihypertensive effect in spontaneously hypertensive rats, J Agric Food Chem, 21, 6245-6252. 
Functional Ingredients from Algae for Foods and Nutraceuticals (Cap.16): 534-560 (2013)

doi: 10.1533/9780857098689.3.534 isbn: 978-0-85709-512-1

Schaich KM (2006), Developing a Rational Basis for Selection of Antioxidant Screening and Testing Methods, Acta Hort, 709, 79-94.

Schneider LS (2012), Could cholinesterase inhibitors be harmful over the long term? Int Psychog, 24, 171-174.

Sekar, S., Chandramohan, M. (2008), Phycobiliproteins as a commodity: Trends in applied research, patents and commercialization, J. Appl Phycol, 20, 113-136.

Shahidi F, Zhong Y (2008), Bioactive peptides, J AOAC Int, 9, 914-931.

Shang, YF, Kim SM, Lee WJ, Um BH (2011), Pressurized liquid method for fucoxanthin extraction from Eisenia bicycles (Kjellman) Setchell, J Biosc Bioeng, 111, $237-241$.

Sheih IC, Fang TJ, Wu TK, Lin PH (2010), Anticancer and antioxidant activities of the peptide fraction from algae protein waste, J Agric Food Chem, 58, 1202-1207.

Simó C, Herrero M, Neusüb C, Pelzing M, Kenndler E, Barbas C, Ibáñez E, Cifuentes A (2005), Characterization of proteins from Spirulina platensis microalga using capillary electrophoresis-ion trap-mass spectrometry and capillary electrophoresis-time of flight-mass spectrometry, Electrophoresis, 26, 2674-2683.

Simon D, Helliwell S (1998), Extraction and quantification of chlorophyll A from freshwater green algae, Water research, 32, 2220-2223.

Soares AR, Abrantes JL, Lopes Souza TM, Leite Fontes CF, Pereira RC, Palmer Paixao Frugulhetti IC, Teixeira, VL (2007), In vitro antiviral effect of meroditerpenes isolated 
Functional Ingredients from Algae for Foods and Nutraceuticals (Cap.16): 534-560 (2013)

doi: 10.1533/9780857098689.3.534 isbn: 978-0-85709-512-1

from the Brazilian seaweed Stypopodium zonale (Dictyotales), Planta Med., 73, 12211224.

Spolaore P, Joannis-Cassan C, Duran E, Isambert A (2006), Commercial applications of micro-algae, J Biosci Bioeng, 101, 87-96.

Stirk WA, Reinecke DL, Van Staden J (2007) Seasonal variation in antifungal, antibacterial and acetylcholinesterase activity in seven South African seaweeds, $J$ Appl Phycol, 19, 271-276.

Sturm BSM, Peltier E, Smith V, Denoyelles F (2012), Controls of microalgal biomass and lipid production in municipal wastewater-fed bioreactors, Environ Prog Sustainable Energy, 31, 10-16.

Suetsuna K, Nakano T (2000), Identification of an antihypertensive peptide from peptic digest of Wakame (Undaria pinnatifida), J Nutr Biochem, 9, 450-454.

Suganthy N, Karutha Pandian S, Pandima Devi K (2010), Neuroprotective effect of seaweeds inhabiting South Indian coastal area (Hare Island, Gulf of Mannar Marine Biosphere Reserve): Cholinesterase inhibitory effect of Hypnea valentiae and Ulva reticulate, Neurosci Letters, 468, 216-219.

Tabet N (2006), Acetylcholinesterase inhibitors for Alzheimer's disease: Antiinflammatories in acetylcholine clothing!, Age and Ageing, 35, 336-338.

Takamatsu S, Hodges TW, Rajbhandari I, Gerwick WH, Hamann MT, Nagle DG (2003), Marine natural products as novel antioxidant prototypes, J Nat Prod, 66, 605608. 
Functional Ingredients from Algae for Foods and Nutraceuticals (Cap.16): 534-560 (2013) doi: 10.1533/9780857098689.3.534 isbn: 978-0-85709-512-1

Tanaka M, Takamizu A, Hoshino M, Sasaki M, Goto M (2012), Extraction of dietary fiber from Citrus junos peel with subcritical water, Food Bioprod Process, 90, 180-186.

Thillairajasekar K, Duraipandiyan V, Perumal P, Ignacimuthu S (2009), Antimicrobial activity of Trichodesmium erythraeum (Ehr) (microalga) from South East coast of Tamil Nadu, India, Int J Int Biol, 5, 167-170.

Tüney I, Çadirci BH, Ünal D, Sukatar A (2006), Antimicrobial activities of the extracts of marine algae from the coast of Urla (Izmir, Turkey), Turk., J Biol, 30, 171-175.

Turner C, Turner P, Jacobson G, Almgren K, Waldeback M, Sjöberg P, NordbergKarlsson E, Markides KE (2006), Subcritical water extraction and beta-glucosidasecatalyzed hydrolysis of quercetin glycosides in onion waste, Green Chem, 8, 949-59.

Turner C, Ibañez E (2011), Pressurized hot water extraction and processing, in Lebovka N, Vorobiev E, Chemat F, Enhancing Extraction Processes in the Food Industrycontemporary food engineering, Boca Raton, CRC press, 223-255.

Udenigwe CC, Aluko RE (2012), Food protein-derived bioactive peptides: Production, processing, and potential health benefits, J Food Sci, 77, R11-R24.

Usov AI, Bilan MI, Klochkova NG (1992) Polysaccharides of algae. 48. Polysaccharide composition of several calcareous red algae: Isolation of alginate from Corallina pilulifera $\mathrm{P}$ et R (Rhodophyta, Corallinaceae), Botanica Marina, 38, 43-52.

Usov AI, Smirnova GP, Klochkova NG (2001) Polysaccharides of Algae: 55. Polysaccharide Composition of Several Brown Algae from Kamchatka, Russian J Bioorganic Chem, 27, 395-399. 
Functional Ingredients from Algae for Foods and Nutraceuticals (Cap.16): 534-560 (2013) doi: 10.1533/9780857098689.3.534 isbn: 978-0-85709-512-1

Van Leeuwe MA, Villerius LA, Roggeveld J, Visser RJW, Stefels J (2006), An optimized method for automated analysis of algal pigments by HPLC, Marine Chem, $102,267-275$.

Vo TS, Ngo DH, Van Ta Q, Kim SK (2011), Marine organisms as a therapeutic source against herpes simplex virus infection, Eur J Pharm Sci, 44, 11-20.

Vo TS, Ngo DH, Kim SK (2012), Marine algae as a potential pharmaceutical source for anti-allergic therapeutics, Process Biochem, 47, 386-394.

Wang T, Jónsdóttir R, Ólafsdóttir G (2009), Total phenolic compounds, radical scavenging and metal chelation of extracts from Icelandic seaweeds, Food Chem, 116, $240-248$.

Wang T, Jónsdóttir R, Kristinsson HG, Hreggvidsson GO, Jónsson JT, Thorkelsson G, Ólafsdóttir G (2010), Enzyme-enhanced extraction of antioxidant ingredients from red algae Palmaria palmate, LWT - Food Sci Technol, 43, 1387-1393.

Wiboonsirikul J, Adachi S (2008), Extraction of functional substances from agricultural products or by-products by subcritical water treatment, Food Sci Technol Res, 14, 319328.

Wiese M, D’Agostino PM, Mihali TK, Moffitt MC, Neilan BA (2010), Neurotoxic Alkaloids: Saxitoxin and Its Analogs, Mar. Drugs, 8, 2185-2211.

Wijesinghe WAJP, Jeon YJ (2012a), Enzyme-assistant extraction (EAE) of bioactive components: A useful approach for recovery of industrially important metabolites from seaweeds: A review, Fitoterapia, 83, 6-12. 
Functional Ingredients from Algae for Foods and Nutraceuticals (Cap.16): 534-560 (2013) doi: 10.1533/9780857098689.3.534 isbn: 978-0-85709-512-1

Wijesinghe WAJP, Jeon YJ (2012b) Biological activities and potential industrial applications of fucose rich sulfated polysaccharides and fucoidans isolated from brown seaweeds: A review, Carbohydrate Polymers, 88, 13-20.

Wijffels RH (2008), Potential of sponges and microalgae for marine biotechnology, Trends in Biotechnol, 26, 26-31. 


\section{Figure Captions}

Figure 1. Dielectric constant $(\varepsilon)$ of pure liquid water as a function of the temperature, and values corresponding to some common organic solvents at room temperature.

Figure 2. Scheme of the main parts contained in a static SWE.

Figure 3. Fucoidans structure from F. vesiculosus, composed mainly by a disaccharide motif containing sulfate at the 2-position of the 3-linked fucose and sulfate groups on the 2- and 3-positions of the 4-linked fucose. Adapted with permission from (Jiao et al., 2011). MDPI Open Access. 


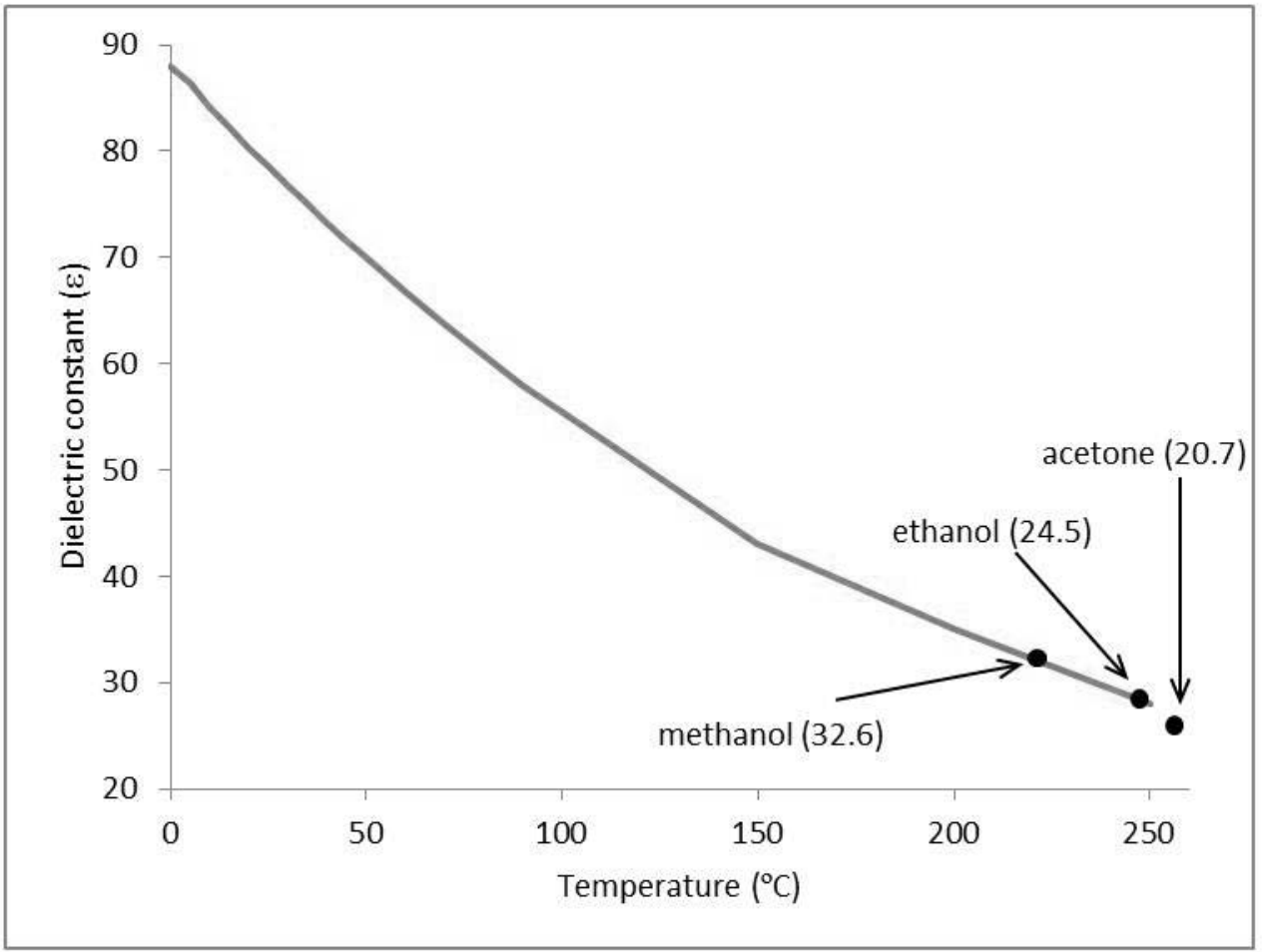




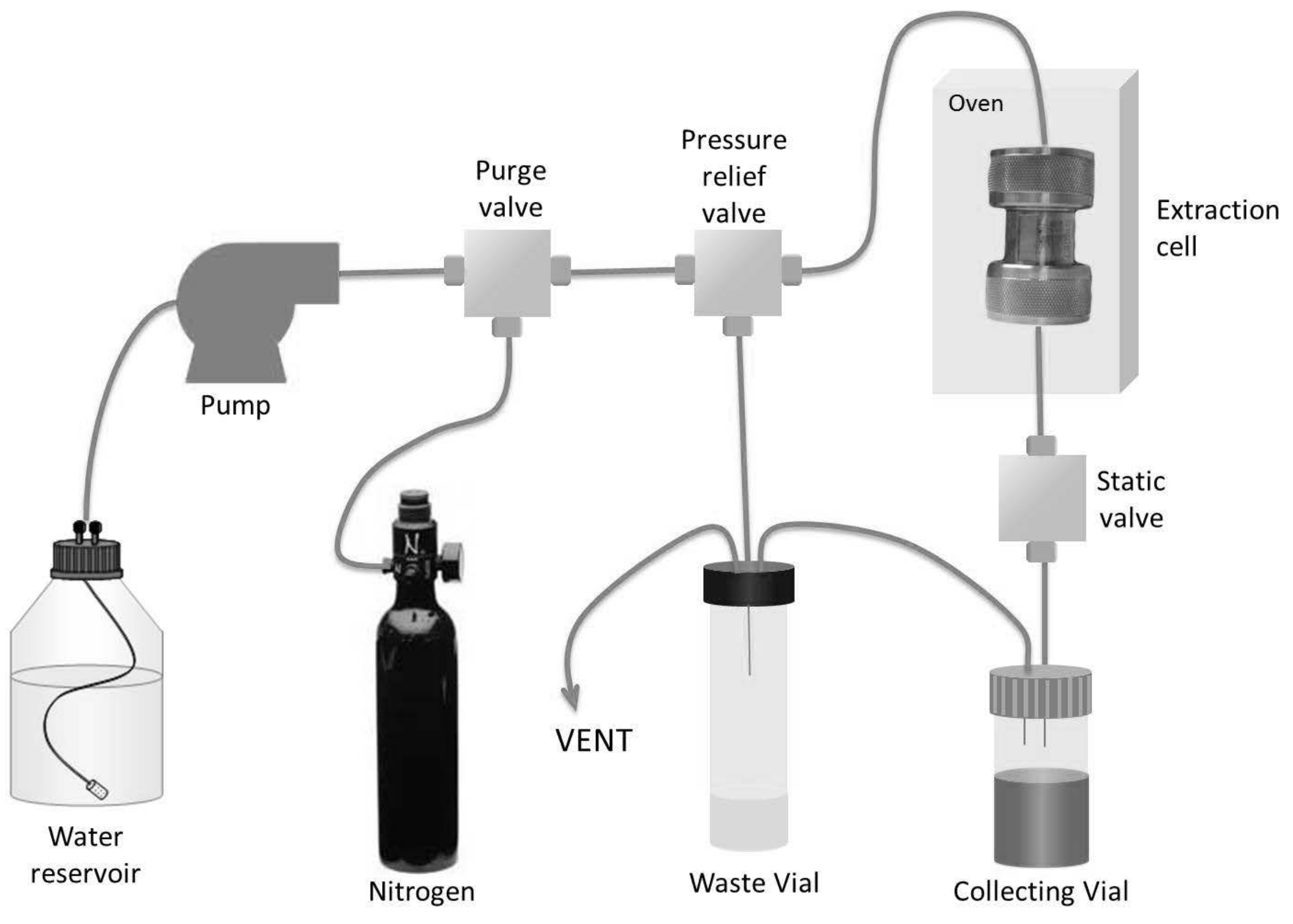


